\title{
Adult-Onset Subacute Sclerosing Panencephalitis Presented with Neuropsychiatric Symptoms
}

\author{
Abdulkerim Gokoglu ${ }^{1}$ and Hasan Tahsin Gozdas²
}

\begin{abstract}
Subacute sclerosing panencephalitis (SSPE) is a progressive neurodegenerative disease caused by persistent infection of the brain with the measles virus. The most clinical presentations are behavioural changes and deterioration of mental status. The diagnosis is made with the characteristic clinical picture along with the consistent laboratory findings such as increased anti-measles antibody levels in cerebrospinal fluid accompanied by typical electroencephalographic and cranial imaging findings. SSPE usually affects children. Adult-onset SSPE is very rare and often presents with atypical features. We report here the case of a 62-year female presented with neuropsychiatric symptoms in whom SSPE was diagnosed based on cerebrospinal fluid, electroencephalographic and cranial imaging findings.
\end{abstract}

Key Words: Subacute sclerosing panencephalitis, Measles virus, Neuropathology.

\section{INTRODUCTION}

Subacute sclerosing panencephalitis (SSPE) is a progressive neurodegenerative disease due to persistent infection of the brain with the measles virus. It is a rare disease characterised by behavioural changes and deterioration of mental status. The diagnosis is made with the characteristic clinical picture and also with consistent laboratory findings such as increased anti-measles antibody levels in cerebrospinal fluid (CSF) accompanied by typical electroencephalographic and cranial imaging findings. ${ }^{1}$ SSPE mainly affects children. Adult-onset SSPE is very rare and often presents with atypical features. ${ }^{2}$

Here, we report the case of a 62-year-old female with neuropsychiatric symptoms due to SSPE.

\section{CASE REPORT}

A 62-year female was admitted with complaints of meaningless speech, short and long-term memory loss, gait and balance disorder. The patient's complaints had started three years before as a depressive episode. Cerebral vasculitis, multiple sclerosis, dementia and psychosis were considered as initial diagnoses. It was learned that there was no apparent improvement in her complaints despite antipsychotic treatment. Complete blood count, biochemical tests, C-reactive protein, erythro-

1 Department of Neurosurgery, Acibadem Hospital, Kayseri, Turkey

2 Department of Infectious Diseases and Clinical Microbiology, Abant Izzet Baysal University Faculty of Medicine, Bolu, Turkey

Correspondence: Dr. Hasan Tahsin Gozdas, Department of Infectious Diseases and Clinical Microbiology, Abant Izzet Baysal University Faculty of Medicine, Bolu, Turkey E-mail:dr.htgozdas@yahoo.com.tr

Received: June 06, 2018; Accepted: November 30, 2018 cyte sedimentation rate, vitamin B12 and folic acid levels were in normal limits. Microbial tests, which might be relevant with the patient's clinical status, were as follows: antitoxoplasma IgM: negative, anti-toxoplasma IgG: positive, antirubella IgM: negative, and antirubella IgG: negative. Cranial magnetic resonance imaging (MRI) showed loss of signal intensities in both cerebral hemispheres, subcortical and periventricular deep white matter. The lesions were as diffuse foci without mass and edema effect. These MRI findings suggested ischemic gliosis foci, atypical demyelinating plaques and vasculitis (Figure 1). An electroencephalo-graphy (EEG) was reported as diffuse background slowing without periodic activity. Further test results were antinuclear antibody: negative, cytoplasmic and perinuclear antineutrophil cytoplasmic antibodies: negative, IL-6: 6.7 $\mathrm{pg} / \mathrm{ml}(\mathrm{N}<5.4)$, homocysteine: $9.67 \mu \mathrm{mol} / \mathrm{L}(\mathrm{N}: 5-15)$, and serum amyloid $\mathrm{A}: 0.86 \mathrm{mg} / \mathrm{dL}(\mathrm{N}<0.5)$. In the $\mathrm{CSF}$ examination, 5 leukocytes and 6500 erythrocytes per $\mathrm{mm}^{3}$ were observed. There was no growth in CSF culture. CSF biochemical analysis revealed glucose: 67 $\mathrm{mg} / \mathrm{dL}$ (concurrent blood sugar: $97 \mathrm{mg} / \mathrm{dL}$ ), protein: 115 $\mathrm{mg} / \mathrm{dL}$ (N: 15-40), sodium: $149 \mathrm{mmol} / \mathrm{L}$ (N:142-150), chlorine: $132 \mathrm{mmol} / \mathrm{L}(\mathrm{N}: 118-132)$, Herpes simplex type 1 and 2 DNA: negative, Toxoplasma gondii DNA: negative, Varicella zoster virus DNA: negative, Borrelia burgdorferi DNA: negative, rickettsia DNA: negative, rubella RNA negative. CSF rubeola IgG was $11.5 \mathrm{mg} / \mathrm{dL}(\mathrm{N}: 0-3.4)$. Serum rubeola IgG was $669 \mathrm{mg} / \mathrm{dL}$ (N: 700-1600). Oligoclonal band was negative in serum and CSF. When the patient's clinical picture, CSF, EEG and cranial MRI findings were evaluated together, the results were thought to be consistent with SSPE.

The patient received amantadine $100 \mathrm{mg}$ orally three times a day followed by clinical and radiological improvement. Control cranial MRI showed regression of the lesions (Figure 2). 


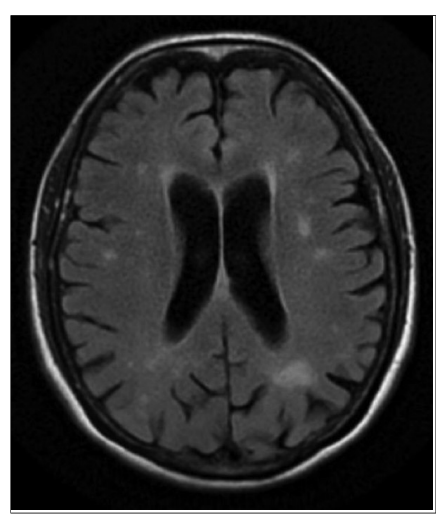

Figure 1: Cranial magnetic resonance image showing multiple nonenhancing nodular lesions with variable dimensions in both cerebral hemispheres, subcortical and periventricular deep white matter.

\section{DISCUSSION}

SSPE usually affects children, but adult-onset SSPE is very rare and may be presented with slowly atypical features such as neuropsychiatric symptoms. Its incidence in Turkey is approximately one per million. 3,4 Negative or undocumented measles exposure is more often seen in adult-onset cases than pediatric cases. Consistently, our patient did not describe any measles exposure.

This patient developed SSPE symptoms for the first time at the age of 59 years. She presented with behavioural and neurological changes and with abnormal EEG finding consistent with SSPE. Cranial MRI demonstrated multiple non-enhancing nodular lesions with variable dimensions in both cerebral hemispheres, peri-ventricular white matter, centrum semiovale and subcortical area. Our patient's lesions was diffusely distributed in the brain and suggested ischemic gliosis foci, demyelinating pathology and vasculitis at first evaluation. Diffuse demyelinating leukoencephalopathy was reported in adult-onset SSPE previously. ${ }^{2}$
Mild CSF pleocytosis, elevated protein and CSF gammaglobulin levels are typical findings of SSPE. CSF IgG measles antibodies show 100\% sensitivity, 93.3\% specificity with $100 \%$ positive predictive value in SSPE. 4 Impaired immune cellular response as well as viral mutations are thought to be important in SSPE pathogenesis. Persistent infection of brain neurons by measles virus eventually occurs. ${ }^{5}$

Cranial MRI findings in this case were similar to previous literature including demyelination, perivascular inflammation and neuronal degeneration. 4,5 There is no certain treatment of SSPE. 5 However, this patient benefited from amantadine treatment. To the best of the authors' knowledge, this case is the first adult-onset SSPE case from Turkey. Adult-onset SSPE may be difficult to diagnose and should be considered when high CSF gammaglobulin levels are found, with or without CSF pleocytosis, in the presence of unexplained neuropsychiatric symptoms and signs.

\section{REFERENCES}

1. Rafique A, Amjad N, Chand P, Zaidi SS, Rana MS, Ahmed K, et al. Subacute sclerosing panencephalitis: Clinical and demographic characteristics. J Coll Physicians Surg Pak 2014; 24: 557-60.

2. Vilas D, Becerra JL, Lozano M, Soriano A, Matas L, Martro E, et al. Atypical presentation of adult-age onset subacute sclerosing panencephalitis. Rev Neurol 2012; 54:60-1.

3. Oncel I, Saltik S, Anlar B. Subacute sclerosing panencephalitis and immune thrombocytopenia: More than a coincidence? Med Hypotheses 2018; 111:70-2.

4. Studart Neto A, Nóbrega PR, Duarte MI, Lucato LT, Castro LH, Nitrini R. Adult-onset subacute sclerosing panencephalitis manifesting as slowly progressive dementia. J Neurovirol 2015; 21:468-71.

5. Jafri SK, Kumar R, Ibrahim SH. Subacute sclerosing panencephalitis - current perspectives. Pediatric Health Med Ther 2018; 9:67-71. 